\title{
Antimicrobial Consumption in Medicated Feeds in Vietnamese Pig and Poultry Production
}

\author{
Nguyen Van Cuong, ${ }_{3}^{1}$ Nguyen Thi Nhung, ${ }^{1}$ Nguyen Huu Nghia, ${ }^{1}$ Nguyen Thi Mai Hoa, ${ }^{1}$ \\ Nguyen Vinh Trung, ${ }^{3}$ Guy Thwaites, ${ }^{1,2}$ and Juan Carrique-Mas ${ }^{1,2}$ \\ ${ }^{1}$ Oxford University Clinical Research Unit, Wellcome Trust Major Overseas Programme, 764 Vo Van Kiet, Ho Chi Minh City, Vietnam \\ ${ }^{2}$ Nuffield Department of Medicine, Oxford University, Oxford, UK \\ ${ }^{3}$ Department of Medical Microbiology, Academic Medical Center, University of Amsterdam, Pietersbergweg 17, 1105 BM Amsterdam, The Netherlands
}

\begin{abstract}
Antimicrobials are extensively used as growth promoters in animal feeds worldwide, but reliable estimates are lacking. We conducted an internet-based survey of commercial chicken and pig feed products officially approved for sale in Vietnam over the period March-June 2015. Information on the antimicrobial contents in feed products, alongside animal production data, was used to estimate in-feed antimicrobial consumption to produce one kilogram of live animal (chicken, pig), as well as to estimate country-wide antimicrobial consumption through animal feeds. A total of 1462 commercial feed formulations were examined. The survey-adjusted estimated antimicrobial contents were 25.7 and $62.3 \mathrm{mg} / \mathrm{kg}$ in chicken and pig feeds, respectively. Overall, it was estimated that $77.4 \mathrm{mg}$ [95\% CI 48.1-106.8] and 286.6 mg [95\% CI 191.6-418.3] of in-feed antimicrobials were used to raise $1 \mathrm{~kg}$ of live chicken and pig, respectively. Bacitracin (15.5\% feeds), chlortetracycline $(11.4 \%)$, and enramycin $(10.8 \%)$ were the most common antimicrobials present in chicken feed formulations, whereas bacitracin $(24.8 \%)$, chlortetracycline $(23.9 \%)$, and florfenicol $(17.4 \%)$ were the most common in pig feed formulations. Overall, $57 \%$ of the total quantitative usage consisted of antimicrobials regarded by WHO of importance for human medicine, including amoxicillin, colistin, tetracyclines, neomycin, lincomycin, and bacitracin. These figures confirm a very high magnitude of in-feed consumption of antimicrobials, especially in pig production. Results from this study should encourage further monitoring of antimicrobials used in animal production, and foster discussion about existing policies on inclusion of antimicrobials in animal feed rations.
\end{abstract}

Keywords: antimicrobial, animal production, antimicrobial drug resistance, Vietnam

\section{INTRODUCTION}

Antimicrobial resistance (AMR) is today one of the most important challenges posed to the health community

Nguyen Van Cuong and Nguyen Thi Nhung have equally contributed to this work. Published online: May 19, 2016

Correspondence to: Juan Carrique-Mas, e-mail: jcarrique-mas@oucru.org globally (WHO 2014). Antimicrobials are extensively used in veterinary medicine to treat and prevent animal diseases. In addition, in many countries they are often added to feedstuffs as antimicrobial growth promoters (AGP) in order to increase productivity (Page and Gautier 2012). Over the years, there has been mounting evidence that the use of antimicrobials in agriculture (including AGP) con- 
tributes to the development of AMR (Alexander et al. 2008; Marshall and Levy 2011; Landers et al. 2012). Although the magnitude of this contribution is unknown, it is likely to be variable depending on the types and quantities of antimicrobials used in each country.

Previous studies have suggested that in Europe and the United States antimicrobials in animal production represent by far the greatest fraction (66-80\%) of the total global antimicrobial usage (McEwen and Fedorka-Cray 2002; Moulin et al. 2008). The total amount of antimicrobials used globally for animal production has been estimated to be 63 thousand tons per year. It is expected that it will continue to increase over the next few years due to intensification of livestock production in emerging economies (Van Boeckel et al. 2015). Over recent decades, Vietnam and other countries in the Asia-Pacific region have been experiencing rapid intensification in their livestock production systems; by 2011, this region represented $48 \%$ of the global veterinary antimicrobial market (Otte et al. 2012).

There are very few quantitative estimates of the use of AGP in animal feeds. Australian import statistics for 19921996 indicated that $55.8 \%$ antibiotics imported were for animal feeds, $7.8 \%$ for 'veterinary use,' and $36.4 \%$ for 'human use' (Barton 2000). To our knowledge, no formal quantitative-qualitative studies on antimicrobials in animal feed rations in Southeast Asia have been published to date. In Vietnam, the Ministry of Agriculture and Development regularly publishes a list of authorized commercial feed products and trading companies (MARD 2012), as well as an official list of antimicrobials banned for livestock and aquaculture (MARD 2014). We carried out an internetbased survey aimed at investigating the types and quantities of antimicrobials present in commercial feed rations aimed at pig and poultry production in Vietnam. Results were used to extrapolate the total amounts of antimicrobials consumed in pig and chicken production based on official production figures.

\section{Materials and Methods}

\section{Types and Amounts of Antimicrobials in Commer- cial Feeds}

The target population was 'commercial feed products aimed at pig and chicken production available in Vietnam during the months March to June 2015.' To achieve this, all listed feed products destined for poultry and livestock listed in Regulation 26/2012/TT-BNNPTNT (MARD 2012) were individually searched using the Google internet search engine over the period March-June 2015. Through this search, the company responsible for marketing each of the products was identified, as well as its location (province). From each feed formulation, the following information was gathered: antimicrobial type (defined as product with known antibacterial activity), antimicrobial concentration (expressed in $\mathrm{mg} / \mathrm{kg}$ feed product), and the target species. We excluded ionophore products, mostly aimed at controlling coccidial infections, since they do not seem to encourage antimicrobial resistance (Callaway et al. 2013). The amount of antimicrobial (mean and standard deviation) in feed formulations aimed for pigs and chickens was calculated assuming equal sales of all products. In addition, each feed product was assigned a sampling weight (Dohoo et al. 2003) consisting of the number of provinces from which each company operated. This ensured that feed products distributed by larger companies (i.e., with greater presence in the country) had a higher contribution to the overall survey estimate, since sales of individual products were not known.

\section{Antimicrobials Used to Produce Chicken and Pig Meat}

The amount of each antimicrobial included in feed to produce one typical chicken and one typical pig was estimated by bootstrap simulation (Selvin 1998) based on 100,000 replicates of the product of the following: (1) probability of a feed product containing a given antimicrobial; (2) amounts of antimicrobial present in each feed product; and (3) estimated amount of feed consumed by each animal produced based on the typical weight of Vietnamese chicken and feed breeds and published 'feed conversion factor' (FCF) data (Table 1). For feed products with ambiguous labeling (i.e., indicating inclusion of one of two or more listed antimicrobials), each of the antimicrobials was assigned with a random probability inversely dependent on the number of antimicrobials listed. For example, for a feed product indicating the inclusion of either antimicrobial A or B, inclusion of each antimicrobial (A or B) was simulated with a probability of 0.5 . These final estimates were converted into the amounts of antimicrobials used to produce one kilogram of pig and chicken meat. To estimate the amount used per week (i.e., intensity of usage), results were divided by the length of the pro- 
Table 1. Sources of Data Used to Carry Out Bootstrap Simulations to Estimate Amounts of Antimicrobial Consumption Through feed Among Chickens and Pigs in Vietnam.

\begin{tabular}{llll}
\hline & Chickens & Pigs & Source \\
\hline Weight at slaughter $(\mathrm{kg})($ mean $\pm \mathrm{SD})$ & $1.77 \mathrm{~kg}( \pm 0.32)$ & $92.50 \mathrm{~kg}( \pm 20.0)$ & Kinh and Hai (2007), FAO (2008) \\
FCF (mean $\pm \mathrm{SD})$ & $2.85( \pm 0.36)$ & $3.90( \pm 0.78)$ & Kinh and Hai (2007), FAO (2008) \\
Duration of production (weeks) & 13.0 & 37.0 & Author’s estimates \\
Annual animal weight production (thousand tons) & $545.0^{\mathrm{a}}$ & 3217.9 & GSO (2015) \\
\hline
\end{tabular}

${ }^{a}$ Assuming that chickens represent $73 \%$ of overall poultry production, according to Desvaux and Ton (2008); FCF feed conversion factor; SD standard deviation.

Table 2. Number of Antimicrobials Reported in 1821 Livestock and Poultry Commercial Feeds Investigated.

\begin{tabular}{|c|c|c|c|c|c|c|}
\hline & Pigs & Chickens & Ducks/muscovy ducks & Quails & Cattle/ruminants & Total \\
\hline No antimicrobials & 303 & 159 & 129 & 30 & 40 & 661 \\
\hline 1 antimicrobial & 231 & 101 & 13 & 7 & 0 & 352 \\
\hline 1 listed & 207 & 91 & 13 & 7 & - & 318 \\
\hline 2 listed & 18 & 10 & - & - & - & 28 \\
\hline 3-5 listed & 6 & - & - & - & - & 6 \\
\hline 2 antimicrobials & 75 & 15 & 0 & 0 & 0 & 90 \\
\hline 3 antimicrobials & 71 & 0 & 0 & 0 & 0 & 71 \\
\hline With antimicrobial & 377 & 116 & 13 & 7 & 0 & 513 \\
\hline Number of products with data & 680 & 275 & 142 & 37 & 40 & 1174 \\
\hline All products investigated & 977 & 485 & 249 & 60 & 50 & 1821 \\
\hline
\end{tabular}

duction cycle, since pig and chicken production cycles have different durations.

\section{Overall Antimicrobial Consumption in Feeds for Chicken and Pig Production}

Overall antimicrobial consumption in feeds in Vietnamese pig and chicken production was simply obtained by multiplying the estimated feed consumption (from official annual production figures in kilograms of live animal and FCF) by the amounts (per weight of feed) of antimicrobials based on the feed survey results. The data sources used to perform all analyses are shown in Table 1. All analyses were carried out using R (www.r-project.org). Survey-adjusted estimates were calculated using the 'survey' package (Lumley 2004).

\section{Results}

\section{Internet-Based Survey of Feed Products}

A total of 1821 commercial feed products were searched in Google: 1500 listed in Regulation 26/2012/TT-BNNPTNT, plus 321 products identified in the searched companies' website. Products were marketed by a total of 297 companies located in 39 provinces across Vietnam. A total of $1462(80.3 \%)$ were products aimed at pigs $(n=977)$ and chickens $(n=485)$. Other products were aimed at ducks/ Muscovy ducks $(n=249)$, quails $(n=60)$, and cattle/ruminants $(n=50)$. Detailed information about the composition (including data about inclusion of antimicrobials) was available for 1174 (64.4\%) feed products. Of those, 513 $(43.7 \%)$ contained at least one antimicrobial. This percent ranged from $55.4 \%$ (377/680) (pig), followed by $42.2 \%$ (116/275) (chicken), 18.9\% (7/37) (quail), and 9.2\% (13/ 142) (duck/Muscovy duck) feeds. None of the 40 cattle/ ruminant feeds with data contained non-ionophore antimicrobials. A total of $5.4 \%$ chicken and $21.5 \%$ pig feed formulations reported the inclusion of two or more antimicrobials. A number of feed products ( 10 chicken and 24 for pigs) reported the potential inclusion of one of several antimicrobials (Table 2). Detailed data about the types and quantities of antimicrobials contained in chicken and pig feed products are presented in Table 3.

Antimicrobials considered of 'critical importance' for human medicine according to $\mathrm{WHO}$ included $\beta$-lactams 
Table 3. Description of the Antimicrobial Contents of Chicken and Pig Commercial Feeds Available in the Vietnamese Market.

\begin{tabular}{|c|c|c|c|c|c|c|c|}
\hline \multirow[t]{3}{*}{ Antimicrobial } & \multirow[t]{3}{*}{ Antimicrobial class } & \multicolumn{3}{|c|}{ Chickens } & \multicolumn{3}{|l|}{ Pigs } \\
\hline & & \multicolumn{2}{|c|}{ Percent feeds containing (\%) } & \multirow{2}{*}{$\mathrm{mg} / \mathrm{kg}( \pm \mathrm{SD})$} & \multicolumn{2}{|c|}{ Percent feeds containing (\%) } & \multirow{2}{*}{$\mathrm{mg} / \mathrm{kg}( \pm \mathrm{SD})$} \\
\hline & & \multicolumn{2}{|c|}{ Unadjusted Adjusted [95\% CI] } & & \multicolumn{2}{|c|}{ Unadjusted Adjusted [95\% CI] } & \\
\hline Chlortetracycline $\mathrm{e}^{\mathrm{b}}$ & Tetracycline & 10.9 & $11.4[7.4-15.5]$ & $81.1( \pm 24.9)$ & 29.8 & $23.9[20.7-27.2]$ & $62.2( \pm 15.2)$ \\
\hline Bacitracin $^{c}$ & Polypeptide & 18.5 & $15.5[10.9-20.1]$ & $71.1( \pm 22.3)$ & 13.2 & $24.7[16.3-47.9]$ & $42.2( \pm 12.8)$ \\
\hline Colistin $^{\mathrm{a}}$ & Polymyxin & 6.9 & $7.4[4.0-10.8]$ & $71.6( \pm 15.2)$ & 9.3 & $12.1[8.9-15.2]$ & $122.4( \pm 35.8)$ \\
\hline Enramycin & Polypeptide & 8.0 & $10.8[6.1-15.4]$ & $13.2( \pm 3.8)$ & 5.3 & $8.0[5.4-10.7]$ & $35.2( \pm 8.5)$ \\
\hline Tylosin & Macrolide & - & - & - & 15.4 & $10.6[8.4-12.9]$ & $40.8( \pm 7.0)$ \\
\hline Florfenicol & Amphenicol & - & - & - & 7.9 & $17.4[13.3-21.4]$ & $96.9( \pm 22.3)$ \\
\hline Lincomycin $^{\mathrm{c}}$ & Lincosamides & 1.1 & $1.33[0.5-2.2]$ & $4.0( \pm 0.0)$ & 0.4 & $1.1[0.2-2.0]$ & $54.3( \pm 14.8)$ \\
\hline Oxytetracycline ${ }^{\mathrm{b}}$ & Tetracycline & - & - & - & 1.5 & $0.9[0.3-1.5]$ & $54.5( \pm 7.9)$ \\
\hline Neomycin ${ }^{a}$ & Aminoglycoside & - & - & - & 0.7 & $0.9[0.3-1.5]$ & $100.0( \pm 0.0)$ \\
\hline Tiamulin & Pleuromutilin & - & - & - & 0.3 & $0.2[0-0.4]$ & $119.0( \pm 3.8)$ \\
\hline Avilamycin & Orthosomycine & 0.4 & $0.2[0.01-0.6]$ & $10.0( \pm 0.0)$ & 0.7 & $0.3[0.1-0.5]$ & $10.0( \pm 0.0)$ \\
\hline Amoxicillin $^{\mathrm{a}}$ & $\beta$-lactam & - & - & - & 0.7 & $1.1[0.2-2.0]$ & $212.0( \pm 42.5)$ \\
\hline Halquinol & Chlorhydroxyquinolone & - & - & - & 0.01 & $0.1[0-0.1]$ & $180.0( \pm 0.0)$ \\
\hline Tylvalosin & Macrolide & - & - & - & 0.1 & $0.3[0-0.9]$ & $100.0( \pm 0.0)$ \\
\hline \multicolumn{2}{|l|}{ Any antimicrobial } & 42.2 & $48.6[41.7-55.6]$ & & 55.4 & $58.8[54.4-63.2]$ & \\
\hline
\end{tabular}

The quantitative data only refer to those products reporting the inclusion of each specific antimicrobial.

CI confidence interval.

'Antimicrobial 'of critical importance.'

bAntimicrobial 'of high importance.'

'Antimicrobial 'of importance' (according to WHO 2011).

(amoxicillin), aminoglycosides (neomycin), and polymyxins (colistin). Antimicrobials considered of 'high importance' included tetracyclines (chlortetracycline, oxytetracycline) and lincosamides (lincomycin). Antimicrobials considered 'of importance' included polypeptides (bacitracin) (WHO 2011). Tylosin and tylvalosin, both macrolide antimicrobials, were only present in pig feed formulations. After adjusting for company supplier, the proportion of feed products with antimicrobials was $58.8 \%$ [95\% CI 54.4-63.2] and 48.6\% [95\% CI 41.7-55.5] for pig and chicken feed products, respectively. Bacitracin (15.5\%), chlortetracycline (11.4\%), and enramycin $(10.8 \%)$ were the most common antimicrobials present in chicken feed formulations, whereas bacitracin (24.8\%), chlortetracycline (23.9\%), and florfenicol (17.4\%) were the most common in pig formulations. The survey-adjusted total content of antimicrobials present in feeds was $25.7 \mathrm{mg} / \mathrm{kg}$ [95\% CI 19.1-32.4] for chicken and $62.3 \mathrm{mg} / \mathrm{kg}$ [95\% CI 54.6-70.0] for pig feed formulations.

\section{Antimicrobials Used to Produce Chicken and Pig Meat}

The estimated amounts of in-feed antimicrobials required to raise one chicken and one pig based on production parameters were, respectively, $137.4 \mathrm{mg}$ [95\% CI 85.3189.2] and 26,178 $\mathrm{mg}$ [95\% CI 17,772-38,692]. The amounts of antimicrobial included in feeds required to raise one kilogram of chicken and one kilogram of pig were $77.4 \mathrm{mg}$ [95\% CI 48.1-106.8] and $286.6 \mathrm{mg}$ [95\% CI 191.6$418.3]$, respectively. The calculated amounts of antimicrobial used per kilogram of live animal produced per week were $6.0 \mathrm{mg}$ [95\% CI 3.70-8.20] for chickens and $8.2 \mathrm{mg}$ [95\% CI 5.2-11.3] for pigs. Bacitracin, chlortetracycline, colistin and enramycin were quantitatively the most commonly used antimicrobials used per kilogram of chicken raised (30.8, 26.0, 14.8, and $3.9 \mathrm{mg}$, respectively), whereas florfenicol, chlortetracycline, colistin, and bacitracin were quantitatively the most common antimicrobials given to 

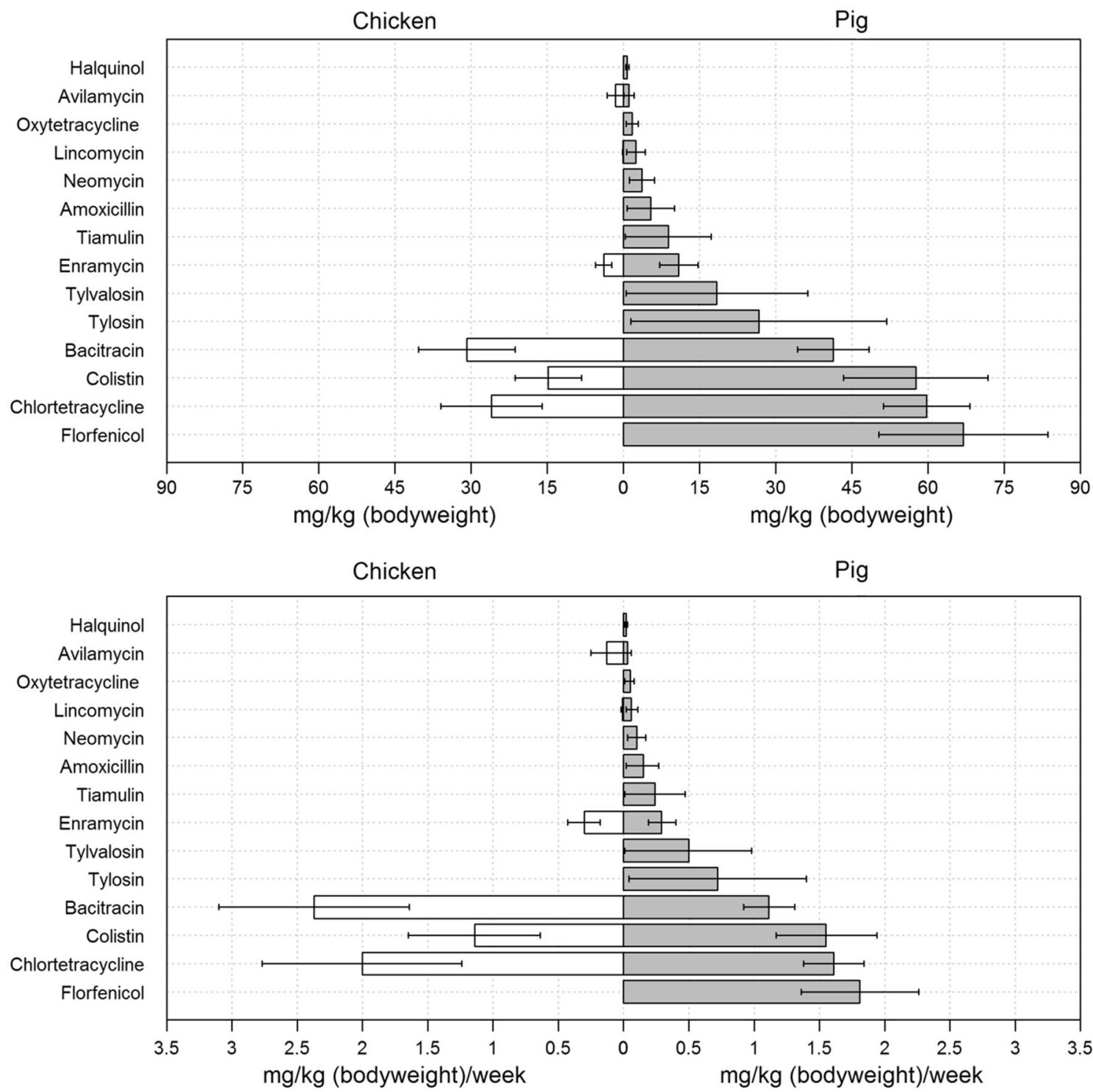

Figure 1. Estimated antimicrobial consumption among Vietnamese chickens and pigs raised with commercial feed rations. The bars represent results (average) obtained from 100,000 simulations. Black lines represent 95\% confidence intervals resulting from the variable probability of inclusion of commercial feeds with each specific antimicrobial

pigs (66.9, 59.7, 57.5, and $41.2 \mathrm{mg}$, respectively). The estimated antimicrobial consumption to raise pigs and chickens is graphically displayed in Fig. 1.

\section{Overall Antimicrobial Consumption in Feeds for Chicken and Pig Production}

The overall estimated amounts of antimicrobials were 1023.5 tons [95\% CI 642.8-1404.2], and 42.2 [95\% CI 26.2-58.2] and 981.3 tons [95\% CI 616.5-1346.0] for Vietnamese chicken and pig production, respectively.
Quantitatively, the most used antimicrobials were, in decreasing order, florfenicol (215.2 tons), chlortetracycline (206.2 tons), colistin (193.3 tons), bacitracin (149.6 tons), and tylosin (85.7 tons). All other antimicrobials were used in quantities less than 40 tons (Fig. 2).

Quantitatively, $57.0 \%$ of total usage (583.6 tons) corresponded to antimicrobials regarded by $\mathrm{WHO}$ as of 'critical importance,' 'of high importance,' or 'of importance' for human medicine, including amoxicillin, colistin, chlortetracycline, neomycin, oxytetracycline, chlortetracycline, and bacitracin. Such antimicrobials represented 


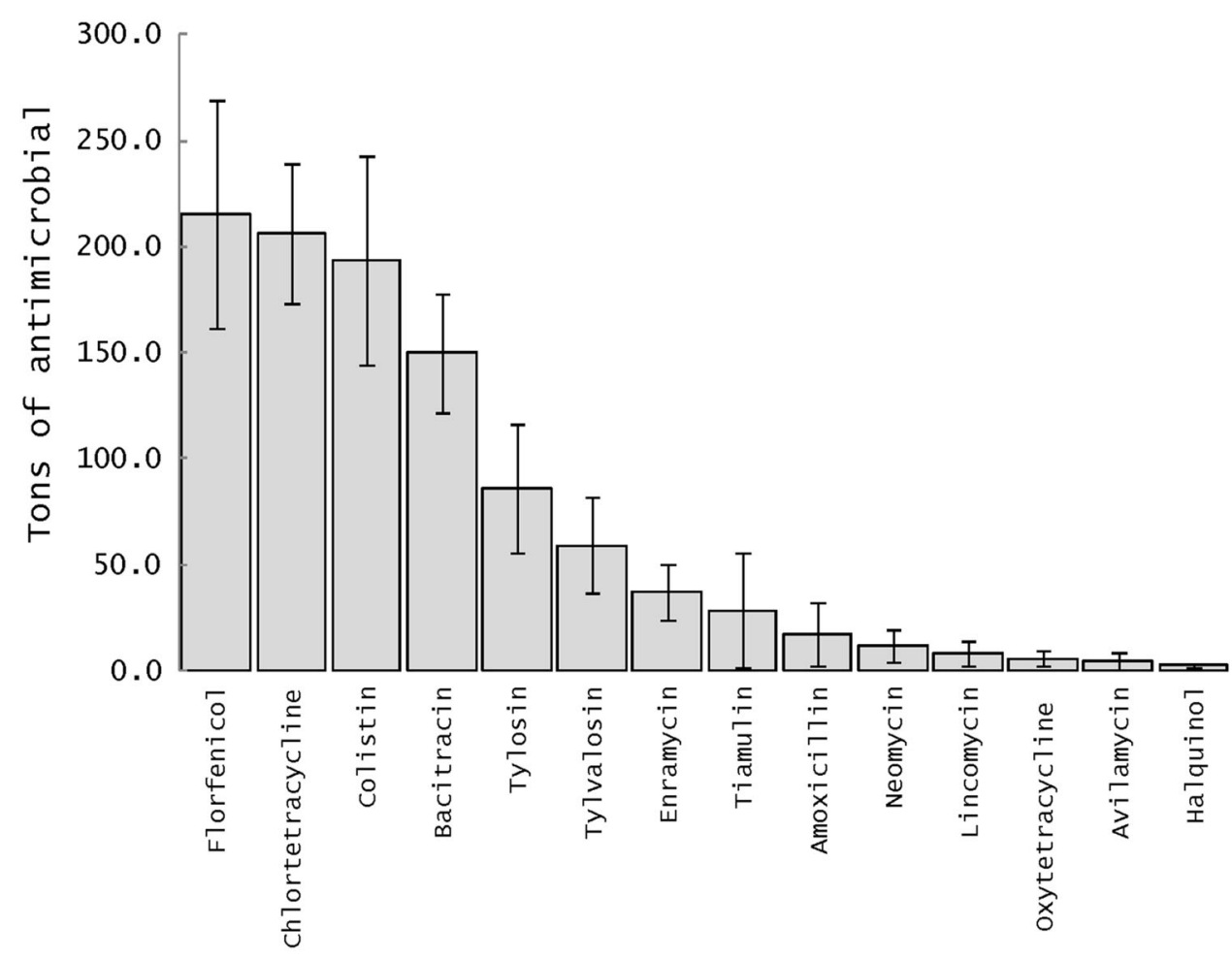

Figure 2. Quantitative estimates of antimicrobials used in chicken and pig production in Vietnam based on animal production figures and survey results
92.6\% (39.1 tons) and 55.5\% (544.5 tons) of total usage for chicken and pig production, respectively.

\section{Discussion}

Our results indicate greater amounts of in-feed antimicrobials to raise one $\mathrm{kg}$ of live pig (286.6 mg) compared with one $\mathrm{kg}$ of live chicken $(77.4 \mathrm{mg})$ and, overall, a much higher magnitude of in-feed usage of antimicrobials in pig production compared with chicken production in Vietnam (981.3 tons vs. 42.2 tons, respectively). This is a reflection of (1) a higher antimicrobial content in pig rations (62.3 $\mathrm{mg}$ vs. $25.6 \mathrm{mg}$ per $\mathrm{kg}$ of feed); (2) the relatively higher feed conversion factor of the pig species (i.e., a higher amount of feed required to produce one kilogram of live animal); and (3) higher levels of pig production, since in Vietnam pork is the main type of meat consumed (35.0 kg per capita per year vs. $12.4 \mathrm{~kg}$ of poultry meat) (FAO 2015). There is a scarcity of global data on the magnitude of use of AGP in animal production. A recent study estimated that $\sim 690$ and $\sim 350 \mathrm{mg}$ of antimicrobials were, respectively, used to raise one $\mathrm{kg}$ of pork and poultry in the USA. However, in that study the fraction of the reported usage corresponding to in-feed antimicrobials was not reported (Krishnasamy et al. 2015).
The overall annual estimates of usage in feeds aimed at pig and chicken production ( $\sim 1023$ tons) represent $1.6 \%$ of the global estimate of $\sim 63$ thousand tons of antimicrobials used for animal production worldwide (Van Boeckel et al. 2015). Although we need to take these figures with caution, these estimates appear to be high in relation to the Vietnam's population (90 million, or $\sim 1.2 \%$ of the world's population), and given that our estimates exclude any other additional antimicrobials supplemented by the farmers to prevent or treat disease.

Our results suggest that in Vietnam antimicrobials used in feed represent $\sim 15-20 \%$ of total antimicrobial usage in chicken production, based on data from a recent survey in the Mekong Delta, where farmers used $690 \mathrm{mg}$ per chicken raised, mostly by adding them in water (Carrique-Mas et al. 2014). Unfortunately, quantitative data on therapeutic and prophylactic antimicrobial usage in pig production are not currently available. Further research efforts are required to fill this important knowledge gap.

The data used in this study have substantial limitations. For example, the sales of each feed product were unknown and some of the formulations were marketed for specific production types (i.e., starter ratio, pig finishing, layer hens, etc.), although this information was not consistently available. In the absence of this information, we chose to correct for the companies' geographical presence, 
assuming that sales of individual products were proportional to the companies' geographical scope, which may not be accurate. Because of this, results have to be interpreted with caution.

We chose to derive antimicrobials consumed in feed from estimated animal production figures, rather than from feed production figures. An industry report (2010) on animal feeds produced in Vietnam indicate a higher overall amount of feeds used (15760 and 2588 thousand tons for pigs and chickens, respectively) vs. our estimates (12550 and 1553 thousand tons for pigs and chickens, respectively). These differences may lead to an underestimation of antimicrobials in feed in our study.

Initial studies carried out several decades ago clearly pointed out important benefits of the use in AGP in terms of overall health and productivity (Dibner and Richards 2005). However, more recent studies have questioned their efficacy in farms managed with higher levels of hygiene and sanitation (Holman and Chenier 2013; Laxminarayan et al. 2015). Countries across the world have variable policies with regard to the use of AGP, ranging from full ban (i.e., European Union countries, Taiwan), to no specific restrictions for the inclusion of antimicrobials in feed (Maron et al. 2013). In Vietnam, antimicrobials can be included in feed formulations subject to approval from the Ministry of Agriculture and Development for each specific commercial product (MARD 2012).

A quantitatively high percentage of antimicrobials administered to chickens and pigs $(92.6 \%$ and $55.5 \%$, respectively) are listed as 'important,' 'very important,' or 'critically important' by WHO (2011). The use of high amounts of colistin is of concern, given that this antimicrobial is regarded as a last resort antimicrobial in patients with multi-resistant gram-negative infections (Le Minh et al. 2015). Recent reports indicate the emergence of $m c r-1$ plasmid-mediated colistin resistance in China (Liu et al. 2016). This gene has also been very recently identified in Vietnamese pigs (Malhotra-Kumar et al. 2016). In addition to its inclusion in commercial feed rations, colistin is widely used in Vietnam and other countries by chicken and pig farmers for prophylactic and therapeutic purposes (Dang et al. 2013; Carrique-Mas et al. 2014). It is suspected that this usage may play a role in selection for the transmission of the mcr-1 gene (Skov and Monnet 2016).

Although antimicrobial resistance against tetracyclines is extensive in enteric bacteria in Vietnam (Nhung et al. 2014; Tu et al. 2015) and elsewhere in Asia (FAO 2014), these antimicrobials are still widely used in Vietnam and elsewhere. Some researchers claim that they are still effective in controlling chronic respiratory infections (Del Pozo Sacristan et al. 2012). The inclusion of this antimicrobial in poultry feeds is of particular concern because of potential residues in eggs (Kodimalar et al. 2014). However, in our study it was not possible to determine whether this antimicrobial was included in feed rations aimed at meat or egg chicken production.

The use of tylosin in pig feeds has been shown to lead to an increase in potentially zoonotic erythromycin-resistant enterococci and staphylococci (Aarestrup and Carstensen 1998). This antimicrobial has considerable impact on the generation of genes that code for cross resistance against macrolides, lincosamides, and streptogramin B (Holman and Chenier 2013). Bacitracin is an antimicrobial often used in ointments to treat skin infections (Spann et al. 2004). Recently, there have been concerns against resistance against this antimicrobial in enterococcal, streptococcal, and staphylococcal human infections (Malhotra-Kumar et al. 2003; Yoshida et al. 2011; Gebhard et al. 2014). This antimicrobial has recently been included in the list of banned antimicrobials published by the Vietnamese government, to be enforced from July 2015 (MARD 2014).

In summary, we investigated the types and quantities of antimicrobials used in feeds aimed at Vietnamese pig and poultry production, and from these data we estimated overall consumption of antimicrobials through feed. Results clearly indicate that pig production use higher amounts of antimicrobials in feed compared with chicken production. These data aim to stimulate discussion as well as provide a baseline for further studies on antimicrobial use in this rapidly emerging economy. We recommend the progressive introduction of restrictions in the use of certain antimicrobials in feed, especially those that are regarded of high/critical importance by WHO. It would also be desirable to monitor the sales of antimicrobials aimed in animal production in Vietnam by additional requirements to the veterinary drug industry and feed mills. These changes should be introduced alongside guidelines to improve disease control by other means such as better hygiene and biosecurity on farms.

\section{ACKNOWLEDGEMENTS}

This work was funded by the Wellcome Trust Major Overseas Programme. JCM was funded by the Wellcome 
Trust through an Intermediate Clinical Fellowship (Grant Ref. No. 110085/Z/15/Z).

\section{Compliance with Ethical Standards}

CONFLICT OF INTEREST The authors declare that they have no conflict of interest.

\section{Open Access}

This article is distributed under the terms of the Creative Commons Attribution 4.0 International License (http:// creativecommons.org/licenses/by/4.0/), which permits unrestricted use, distribution, and reproduction in any medium, provided you give appropriate credit to the original author(s) and the source, provide a link to the Creative Commons license, and indicate if changes were made.

\section{REFERENCES}

Aarestrup FM, Carstensen B (1998) Effect of tylosin used as a growth promoter on the occurrence of macrolide-resistant Enterococci and Staphylococci in pigs. Microbial Drug Resistance-Mechanisms Epidemiology and Disease 4:307-312

Alexander TW, Yanke LJ, Topp E, Olson ME, Read RR, Morck DW, et al. (2008) Effect of subtherapeutic administration of antibiotics on the prevalence of antibiotic-resistant Escherichia coli bacteria in feedlot cattle. Applied and Environmental Microbiology 74:4405-4416

Barton M (2000) Antibiotic use in animal feed and its impact on human health. Nutrition Research Reviews 13:279-299

Callaway TR, Edrington TS, Rychlik JL, Genovese KJ, Poole TL, Jung YS, et al. (2013) Ionophores: their use as ruminant growth promotants and impact on food safety. Current Issues in Intestinal Microbiology 4:43-51

Carrique-Mas J, Trung NV, Hoa NT, Mai HH, Thanh TT, Campbell J, et al. (2014) Antimicrobial usage in chicken production in the Mekong delta of Vietnam. Zoonoses Public Health 61(Suppl. 2):1-9

Dang PK, Saegerman C, Douny C, Ton VD, Bo HX, Binh DV, et al. (2013) First Survey on the use of antibiotics in pig and poultry production in the red river delta region of Vietnam. Food and Public Health 3:247-256

Del Pozo Sacristan R, Rodriguez AL, Sierens A, Vranckx K, Boyen F, Dereu A, et al. (2012) Efficacy of in-feed medication with chlortetracycline in a farrow-to-finish herd against a clinical outbreak of respiratory disease in fattening pigs. Veterinary Record 171:645

Desvaux S, Ton VD (2008). A general review and a description of poultry production in Vietnam. Available: http://avian-influenza. cirad.fr/training_publications/publications/poultry_production_ in_vietnam_cirad_prise_cirrd_niah_jan_2008 [accessed 12 Apr 2015].

Dibner JJ, Richards JD (2005) Antibiotic growth promoters in agriculture: history and mode of action. Poultry Science 84:634643
Dohoo I, Martyn W, Stryhn H (2003) Veterinary Epidemiologic Research, Charlottetown: AVC Inc.

FAO (2008). Poultry production systems in Vietnam. GCP/RAS/ 228/GER Working Paper No. 4. Available: http://www.fao.org/ docrep/013/al693e/al693e00.pdf (accessed 19 April 2015).

FAO (2014). Review of the literature on antimicrobial resistance in zoonotic bacteria from livestock in East, South and Southeast Asia. Available: http://cdn.aphca.org/dmdocuments/REP AMR_141022_c.pdf [accessed Sep 19, 2015].

FAO (2015). Food supply statistics—food and agriculture organization of the United Nations (Statistics Division). Available: http://www.fao.org/statistics/en/ [accessed Jul 30, 2015].

General Statistics Office (GSO) (2015). Statistics yearbook, Vietnam 2013. Available: http://www.gso.gov.vn/default_en.aspx? tabid=515\&idmid=5\&ItemID=14079 [accessed 12 April 2015].

Gebhard S, Fang C, Shaaly A, Leslie DJ, Weimar MR, Kalamorz F, et al. (2014) Identification and characterization of a bacitracin resistance network in Enterococcus faecalis. Antimicrob Agents Chemother 58:1425-1433

Holman DB, Chenier MR (2013) Impact of subtherapeutic administration of tylosin and chlortetracycline on antimicrobial resistance in farrow-to-finish swine. FEMS Microbiology Ecology $85: 1-13$

Kinh LV, Hai LT. (2007). Improving pig performance through breeding and feeding in Vietnam. In: Pig systems in Asia and the Pacific: How can research and development enhance benefits to the poor? ILRI, 23-24 November 2006, Bangkok, Thailand. Available: http://www.ilri.org/InfoServ/Webpub/fulldocs/Pig \%20Systems_proceeding/CH_08_Kinh_Hai.pdf [accessed 21 April 2015].

Kodimalar K, Rajini RA, Ezhilvalavan S, Sarathchandra G (2014) A survey of chlortetracycline concentration in feed and its residue in chicken egg in commercial layer farms. Journal of Biosciences 39:425-431

Krishnasamy V, Otte J, Silbergeld E (2015) Antimicrobial use in Chinese swine and broiler poultry production. Antimicrobial Resistance and Infection Control 4:17

Landers TF, Cohen B, Wittum TE, Larson EL (2012) A review of antibiotic use in food animals: perspective, policy, and potential. Public Health Reports 127:4-22

Laxminarayan R, Boeckel T, and Teillant A (2015). The economic costs of withdrawing antimicrobial growth promoters from the livestock Sector. OECD Food, Agriculture and Fisheries Papers. OECD Food, Agriculture and Fisheries Papers, No. 78, OECD Publishing. Available: http://dx.doi.org/10.1787/5js64kst5wvl-en [accessed 27 July 2015].

Le Minh V, Khanh Nhu NT, Vinh Phat V, Thompson C, Huong Lan NP, Thieu Nga TV, et al. (2015) The in vitro activity of colistin in antimicrobial combination against carbapenem resistant Acinetobacter baumannii isolated from patients with ventilator associated pneumonia in Vietnam. Journal of Medical Microbiology 2015:2015. doi:10.1099/jmm.0.000137

Liu Y, Wang Y, Walsh TR, Yi LX, Zhang R, Spencer J, Doi Y, Tian G, Dong B, Huang X, Yu LF, Gu D, Ren H, Chen X, Lv L, He D, Zhou H, Liang Z, Liu JH, Shen J (2016) Emergence of plasmidmediated colistin resistance mechanism MCR-1 in animals and human beings in China: a microbiological and molecular biological study. The Lancet Infectious Diseases 16:161-168

Lumley T (2004) Analysis of complex survey samples. Journal of Statistical Software 9:1-19

Malhotra-Kumar S, Xavier BB, Das AJ, Lammens C, Hoang HT, Pham NT, Goossens H (2016) Colistin-resistant Escherichia coli 
harbouring mcr-1 isolated from food animals in Hanoi, Vietnam. The Lancet Infectious Diseases 2016:2016

Malhotra-Kumar S, Wang S, Lammens C, Chapelle S, Goossens H (2003) Bacitracin-resistant clone of Streptococcus pyogenes isolated from pharyngitis patients in Belgium. Journal of Clinical Microbiology 41:5282-5284

MARD (Ministry of Agriculture and Development, Government of Vietnam) (2012). Circular 26/2012/TT-BNNPTNT. Promulgation of the provisional list of livestock and poultry feeds authorised in Việt Nam [in Vietnamese]. Available: http://chicucthuyhcm.org.vn/Luat/26-2012-TT-BNNPTNT.aspx [accessed 7 March 2013].

MARD (Ministry of Agriculture and Development, Government of Vietnam) (2014). Circular 28/2014/TT-BNN Promulgation of the list of chemicals, antibiotics prohibited from importation, production, trade and use in livestock and poultry feeds in Vietnam. Available: http://tailieu.vn/doc/thong-tu-so-28-2014tt-bnnptnt-1727942.html [accessed 27 March 2015].

Maron DF, Smith TJ, Nachman KE (2013) Restrictions on antimicrobial use in food animal production: an international regulatory and economic survey. Global Health 9:48

Marshall BM, Levy SB (2011) Food animals and antimicrobials: impacts on human health. Clinical Microbiology Reviews 24:718733

McEwen S, Fedorka-Cray PJ (2002) Antimicrobial use and resistance in animals. Clinical Infectious Diseases 34(Suppl3):S93S106

Moulin G, Cavalie P, Pellanne I, Chevance A, Laval A, Millemann Y, et al. (2008) A comparison of antimicrobial usage in human and veterinary medicine in France from 1999 to 2005. Journal of Antimicrobial Chemotherapy 62:617-625

Nhung NT, Cuong NV, Hoang NVM, Campbell J, Hoa NT, Bryant JE, et al. (2014) High levels of antimicrobial resistance among Escherichia coli isolates from livestock farms and synanthropic rats and shrews in the Mekong Delta of Vietnam. Applied and Environmental Microbiology 81(3):1-9
Otte J, Pfeiffer D, and Rushton J (2012). Antimicrobial use in livestock production and antimicrobial resistance in the AsiaPacific region. Available: http://cdn.aphca.org/dmdocuments/ RBR_1210_APHCA\%20AMR.pdf [accessed 24 September 2015].

Page SW, Gautier P (2012) Use of antimicrobial agents in livestock. Rev Sci Tech 31:145-188

Selvin S (1998) Modern applied biostatistical methods using S-Plus, New York: Oxford University Press

Skov RL, Monnet DL (2016) Plasmid-mediated colistin resistance (mcr-1 gene): three months later, the story unfolds. Eurosurveillance 21(9):30155

Spann CT, Taylor ST, Weinberg JM (2004) Topical antimicrobial agents in dermatology. Disease-a-Month 50:407-421

Tu LPT, Hoang NV, Cuong NV, Campbell J, Bryant JE, Hoa NT, et al. (2015) High levels of contamination and antimicrobial resistant non-typhoidal Salmonella serovars on pig and poultry farms in the Mekong Delta of Vietnam. Epidemiology and Infection 143:3074-3086. doi:10.1017/S0950268815000102

Van Boeckel TP, Brower C, Gilbert M, Grenfell BT, Levin SA, Robinson TP, et al. (2015). Global trends in antimicrobial use in food animals. PNAS:5649-5654.

WHO (2011). Critically important antimicrobials for human medicine (third revision). Availalble: http://www.who.int/ foodsafety/publications/antimicrobials-third/en/ [accessed 15 Apr 2015].

WHO (2014). Antimicrobial Resistance: Global Report on surveillance. Available: http://www.who.int/drugresistance/ documents/surveillancereport/en/ [accessed 1 July 2015].

Yoshida Y, Matsuo M, Oogai Y, Kato F, Nakamura N, Sugai M, et al. (2011) Bacitracin sensing and resistance in Staphylococcus aureus. FEMS Microbiology Letters 320:33-39 